\title{
Standards and Performance Indicators in Higher Education in Romania
}

Internal Concordance Benchmarking against the criteria of the Romanian Quality Assurance

Methodology and Romanian Quality National Award „Juran” in the Bucharest Academy of

Economic Studies

\section{Prof. Ion Gh. ROŞCA, Ph.D., Prof. Ion PLUMB, Senior Lecturer Anca Gabriela ILIE Ph.D Ph.D, Prof. Roxana SÂRBU Ph.D. \\ The Bucharest Academy of Economic Studies}

Motto: There is always a better way... your challenge is to find it.

Keywords: excellence, performance, quality management, quality assurance, quality indicators

\section{Introduction}

The issue of quality in higher education has been given attention in the academic and legislative environment starting with the Bologna Process.

Up to that moment, everyone considered it their duty as a professor to keep up a certain academic standard, which was in fact synonymous with a high quality of the message sent to the students in a manner assumed to be impeccable. It was normal then, as it is now, to present the latest developments in a given domain at the lecture, what you considered to be the most interesting aspects, and to assess whether you have reached your goal by the audience's reactions. It was normal to openly hold a lecture, to ask and be asked questions.

However, society has evolved and certainties are needed nowadays instead of assumptions, as far as quality is concerned.

The Bologna process has changed higher education not only in terms of structure, but also in terms of the place that quality assurance holds in the activity of a university. Together with the Bologna Process, the Lisbon Strategy has led to the development and consolidation of universities, with a view to instating a quality culture, to providing confidence in educational services, as well as transparency and a continuous enhancement of quality $[2,6]$.

\section{Quality assurance in higher education}

The Bucharest Academy of Economic Studies (A.E.S.) is and intends to remain the most prestigious institution of tertiary economic and public administration education in Romania and to rank among the leading universities in Europe (part of its mission) due to the content and topics of its learning processes, its innovation, dynamism, and its involvement, through strategic partnership relations, in the national and international economic environment.

By carrying out its education programs, the A.E.S. provides the Romanian society in general, the national economy in particular, with economists and public administration specialists. Also, it enables students to continue their studies by Master's, post-graduate and Doctor's programs.

The intense research activities within the A.E.S. are pointed out by the numerous and considerable competitive research grants, as well as by research reports and syntheses, systems, models, copyright products, program products, modernization and economic efficiency enhancing solutions, representations in academies or local and international organizations. 
Partnerships with over 50 well-known universities abroad have been established with a view to gaining recognition for the A.E.S. among the prestigious economic institutions worldwide.

A three-cycle structure of education has been yet applied starting with the academic year 2005/2006:

1.Bachelor's degree (B.A. in Economics) - provides a large number of students with basic theoretical knowledge in each specialization; the level of skills and competencies required in the labor market shall be ensured, so that graduates of the first cycle can be immediately employed in an executive position, if they so desire.

2. Master's degree - ensures narrow specializations, providing advanced knowledge and analytical and synthesizing skills specific to executive positions in every field. In addition, it can also decide to offer MBA or Executive MBA Master-type programs.

3.Doctor's degree - aims at educating the scientific élite of economists.

Other educational programs organized by A.E.S. are:

- Postgraduate studies of specialization and improvement

- Postgraduate schools of academic studies: MBA Romanian-Canadian Program, INDE-Program Executive MBA and others.

At the European level, quality has always been the center of attention, being regarded as one of the success factors of the Bologna process. Its importance has increased with each meeting of the line ministers (Prague 2001, Berlin 2003, Bergen 2005) [2].

Once the European Standards and Guidelines for Quality Assurance in Higher Education appeared, what is referred to as quality in higher education has acquired an ever clearer shape. However, attention was not focused on the entire quality management system, but only on one of its parts: quality assurance, centered on creating confidence that quality demands shall be met.

The quality assurance system in higher education refers to the mechanism by means of which the university grants, both to the internal clients (employees, students) and to the external ones, confidence that all the conditions are met to attain the assumed standards. It can be defined as a set of policies, systems and processes directed at the maintenance and enhancement of educational quality, relying on constant assessment and comparison between intended results and obtained results, with a view to identifying sources of dysfunctional activities.

Quality assurance was meant to be achieved at three levels: at a primary, institutional level, raising awareness towards achieving quality, towards a quality-oriented culture and creativity projects; at a national, ideal level, by creating a partnership between higher education institutions, government and agencies, with the intention of developing procedures and requirements to assess conformity; and at a European level, aiming at the universities being attested by European institutions, in order to turn these universities into strong competitors to those in the USA, Japan, Singapore, India and China.

The European Standards and Guidelines for Quality Assurance in Higher Education include requirements both for internal and external quality assurance within higher education institutions. In the case of internal quality assurance, formal statements are required about the expected practice in a university, regarding: policy and procedures for quality assurance; approval, monitoring and periodic review of programs and awards; assessment of students; quality assurance of the teaching staff; learning resources and student support; information systems and public information [5]. 
The external quality assurance is assessed on the basis of the following standards: use of internal quality assurance procedures; development of external quality assurance processes; criteria for decisions; processes fit for purpose; reporting; follow-up procedures; periodic reviews; system-wide analyses [5].

Concerns about the Romanian education system have naturally been affected by the conceptual and practical turmoil existent both at the European and the international level.

In Romania, the legislative / normative framework of assuring the quality of educational services in higher education institutions is provided by Law no. 87 / 2006 to approve the Emergency Ordinance on assuring the quality of education no. 75/12.07.2005, by Order No. 3928/21.04.2005 of the Ministry of Education and Research on ensuring the quality of educational services in higher education institutions, as well as by the Methodology of External Evaluation, the standards and reference standards of the Romanian Agency for Quality Assurance in Higher Education (ARACIS).

At the national level, quality assurance in education refers to the set of policies, processes and actions of public authorities aimed at maintaining and developing quality in education, nationwide.

According to these normative acts, "quality assurance in education is achieved by means of a group of actions aimed at developing the institutional capacity to elaborate, plan and implement education programs; thus, recipients become confident that quality standards are met by the education supplying institution. Quality assurance expresses the capacity of a supplying organization to offer education programs, according to the announced standards. It is promoted in order to lead to the continuous enhancement of education quality" [4].

Among the main objectives of quality assurance are the following: supplying information about the functioning of the education system, about results and possible ways to improve them; taking responsibility for creating conditions favorable to attaining quality; maintaining and improving high academic standards; proving a high quality of academic or professional training programs for all students in a higher education institution; developing an institutional culture of quality and of providing real protection to its education recipient - the student.

Therefore, in order to obtain real quality of the educational act, the following aspects are of crucial importance:

1. the objectives of the educational act, the competence level and the curricula;

2. the study environment, the competence of the teaching staff, of the technical auxiliary staff and the efficiency of work practices;

3. the independent assessment of, on the one hand, the didactic and research activity and, on the other hand, the students' results;

4. a functional education system and sufficient financial resources.

Under Romanian law, as well as in the ARACIS Methodology, the assurance of quality in education refers to the following domains: institutional capacity, educational efficiency and quality management; for each of these, standards and criteria are defined.

ARACIS has taken things to the next level by supplying in its methodology, apart from the quality assurance standards compliant to the European ones, a list of performance indicators on the basis of which universities can be assessed.

Due to the nature of the criteria, standards and performance indicators, the focus is not only on the fulfillment of a predefined set of quantitative and qualitative conditions, but also on the deliberate, intended and pro-action commitment of the higher education institution to attain certain performances which effective results can demonstrate. 
These standards correspond to the domains and criteria of quality assurance in education, while the performance indicators measure the extent to which an activity has been completed by reference to the standards. The standards are expressed in terms of rules or results and they define the minimal compulsory degree in which an educational activity can be completed (its performance indicators).

Unlike these, the reference standards are those standards which define an optimal level where an activity can be completed by an education supplying organization, relying on the good practices existent at the national, European or international level. These can vary from one educational institution to another; thus, there is the possibility that universities may create their own standards, at the highest possible level, competitive nationally and internationally [8].

However, the quality of the educational process cannot be measured solely by calculating quantitative indicators of the type: number of students per professor, the capacity of lecture rooms, of the laboratories, libraries etc. There are a series of specific indicators in this domain, among which: the academic, psychological and pedagogical competence of the teaching staff, the capacity to satisfy the social needs and demand, the moral aspects of a university's activity; student satisfaction; the cultural, ethical and social responsibility of a university; employment and labor conditions offered to staff; academic mobility etc. [1]

In 2007, after an internal benchmarking against all the standards and indicators (a part of these are described below), of the Romanian Agency for Quality Assurance in Higher Education Methodology - ARACIS, A.E.S. requested a periodical institutional certification along these lines. Also, the following were elaborated and evaluated: 15 files for periodical certification of the graduation programmes full-time courses, 87 files for accrediting Master programmes; 9 files for accrediting distance education university studies; one file with a view to approving the capacity of A.E.S. as an institute supplying programmes of training the teaching staff and the authorization of functioning of D.P.P.D. (Department for Training the Teaching Staff). All these programs were then externally evaluated by ARACIS and the institutional level we obtained included the epithet: "high confidence level".

It is worth mentioning that the Romanian standards, criteria and indicators for quality assurance in higher education are correlated with the Standards and Guidelines for Quality Assurance in the European Higher Education Area, 2005.

Some of the standards and performance indicators of quality assurance in Romanian higher education that were taken into account in the development of the internal concordance benchmarking were:

\section{Institutional Capacity}

- Institutional, Administrative and Managerial Entities

1. Mission statement and objectives: Tradition, vision, mission and objectives are what make a difference in the European Higher Education Area.

2. Academic integrity: A.E.S. has a University Ethics code that protects the values of academic freedom, university autonomy and ethic integrity. The application and the analysis of the Code are monitored by the Ethics Committee of A.E.S.

3. Public Responsibility: In A.E.S., academic audit is focused on two components: the quality of the education and research process as well as management activities. The results of the audit are published in an annual report. After the analysis, programs to improve quality are drafted. 


\section{- Management and Administration}

1. Management system: A.E.S. has a coherent, integrated and transparent academic management that is based on an efficient and effective administration, adapted to its mission and objectives. The management system consists of the rector, 6 vice rectors, a chancellor, a general director and a head secretary. The selection mechanism is democratic, transparent, non discriminatory and does not limit the right of the students to represent and to be represented.

2. Strategic Management: A.E.S. has annual plans, an institutional strategic plan and a Strategy for the development of A.E.S. Bucharest 2007-2014.

3. Efficient administration: A.E.S. has an administration that respects the legal provisions and is efficient in the aspect of structure, number and qualifications of the personnel. It has control and continuous development mechanisms represented by the department of Internal Audit and Administration Control. All the projects and reports are elaborated and then reviewed and approved in the A.E.S. Senate.

\section{Material Basis}

\section{- Patrimony, facilities and allotted resources:}

A.E.S. has a patrimony that contributes effectively to the realization of the set mission and objectives.

1. Education, research and other activities: The education and research activities are conducted in classrooms, seminar rooms, laboratories (108 laboratories that ensure education and research in optimum conditions) -each has calculus technique, multimedia systems. The accommodation of the students takes place in 20 student hostels with a capacity of about 5,795 students and 2 buildings for the accommodation of teachers and personnel.

2. Facilities: The classrooms are available with teaching, learning and communication equipment that facilitate the activity of the professors and the reception of each student (video projector, computer, projection screen, video conference equipment, TV studio and flipcharts). Furthermore, in some buildings there is access to wireless networks, including appropriate furniture.

3. Financial resources: A.E.S. is financed by its own financial resources and also by resources coming from $3^{\text {rd }}$ parties. It has a realistic annual budget as well as a 3 year budget. Moreover, there are consistent financial reserves, both of its own (tuition fees, revenues of its departments, sponsorships) and also amounts received from the Romanian Ministry of Education as basic financing.

4. The grant approval system and other forms of material support for students: A.E.S. has and applies a rulebook about the representation and social activity of students, where the types of grants and the conditions necessary to be fulfilled are described.

\section{Educational Efficiency}

Contents of study programs:

- Principles of admission policy for the offered study programs: A.E.S. has its own recruiting and admission policy that is applied without discrimination. Methodologies for the admission, degree, distance learning, post graduate studies and the offer for the number of positions available are made public with at least 6 months before the admission exam.

- Admission practices: admission is based on results obtained in the high school years (20\%), school-leaving examination (10\%) and multiple choice test (70\%).

Scientific research activities: 
- Programming research - long term development strategy;

- Realization of research-procedures of execution;

- Capitalization of research- magazines, scientific sessions, symposiums, seminars, conferences.

\section{Quality Management}

- Existence and application of rules regarding initiation, approval, monitoring and periodic evaluation of study programs: at the end of the academic period, the committee for evaluating and ensuring quality analyses the satisfaction level of the clients of the university; periodically a revision of the structure of education programs takes place. Furthermore, the Central committee develops an internal evaluation report regarding the quality of educational services;

- Connection between degree and qualifications: the structure of the education, bachelor or doctorate is reviewed periodically based on benchmarking with other universities. The monitoring and periodical review of study programs rely on the feedback from students, master's students or doctoral students.

- Transparent procedures of evaluating the study results for students - Student evaluation - the university has a rigorous and consistent means of evaluating students that is applied regularly;

- Procedures of evaluating the professorial body:

1. Student versus professors: the number of professors has to be adequate to the number of students, so that there is an optimum learning process; the evaluation is realized through a questionnaire that is delivered by a neutral person. The questionnaires are not signed, they are sealed and put into an envelope and then delivered to the head of staff.

2. Peers evaluation: this is achieved through periodic evaluation of the quality of the education personnel.

3. Self evaluation of professors;

4. Evaluation by the AES management [3].

\section{Excellence in educational services}

Before 2005, when the "European Standards and Guidelines for Quality Assurance in Higher Education" was adopted in Bergen, the only reference point in the domain of quality in higher education was considered the ISO 9001 standard. This was generically applied to all quality management systems, regardless of the activities carried out in an organization. This offers general principles and requirements leading to the coordination of activities aimed at orienting and controlling an organization in terms of quality [7]. By implementing a quality management system in a university, its capacity to meet objectives in one domain could be assessed; however, the quality of educational services provided in the higher education institution and its capacity to attain the quality level specific to the academic environment could not be assessed.

In order to help education institutions, the ISO IWA 2 standard appeared in 2003: "Quality Management Systems. Guideline for the Application of ISO 9001:2000 in Education" (revised in 2007), adopted as a Romanian standard in 2006. It did not add anything to, did not replace or modify the requirements of ISO 9001: 2000; it was conceived with a view to allowing a clear understanding of the ISO 9001:2000 and ISO 9004:2000 standards' requirements and of the way in which they are implemented in the education area [7]. 
The reason for adopting this international agreement relies on the fact that education curricula and syllabuses provide subjects to be taught, their short description, such as the assessment method; however, they supply no information about the extent to which they meet the recipients' needs and expectations, in case there is any dysfunctional activity in the educational processes.

The principles of the quality management system depend on the domain of educational services (not only in higher education), to which other four specific principles are added, all facilitating success: creating learner value, focusing on social value, agility and autonomy.

The quality management system in education must be understood by also taking into account the curriculum, the learning processes system, the organizational structure, the responsibilities, processes and resources that ensure the quality of all activities carried out in education, not only those strictly connected to the teaching act.

However, given the fact that the quality management system is wider than the quality assurance system, the relation between the two being that of whole - part, the requirements specific to the first, described in the applicable standard, will exceed those of the second. The following processes (indicators to be calculated, filed documents and instruments to use) can serve as examples of such specific requirements: identifying preventive action, providing security, safety and civil protection services, deciding which measurements will be of value to monitor, measurement of variables related to learners, teaching and support staff, performance outcomes from the quality management system, costs analysis related to the achievement of quality objectives, financially focused methodologies to ensure that the expenditures are justified in relation to the resulting benefits, employee survey and suggestion schemes etc. [7].

All these provisions, additional to the requirements of a quality assurance system are natural, if we think that IWA 2 was conceived to allow a clear understanding of ISO 9004, which supplies guidelines with a view to taking into account both the effectiveness and the efficiency of a quality management system and, consequently, the potential for enhancing an organization's performances, paving the way towards excellence models.

Although both in European regulations and in national ones, a quality culture is mentioned, all the standards leading to a quality assurance strategy are far from illustrating what quality culture is really about. Quality culture refers to tasks, standards and responsibilities of individuals, units and processes, and to psychological aspects: understanding, flexibility, participation, hopes and emotions [6].

Quality culture is imposed by the exigency level of excellence awards. The Baldrige National Quality Program - Education Criteria for Performance Excellence falls under the category of excellence methods applicable to education institutions. The evaluation framework includes 7 categories: Leadership; Strategic Planning; Customer Focus; Measurement, Analysis, and Knowledge Management; Workforce Focus; Process Management and Results.

This award is based on TQM philosophy and evaluates the whole university and its associated activities (environment, relationships and challenges) from a system perspective. It promotes awareness of performance excellence as an increasingly important element in competitiveness and sharing information about successful performance strategies and the benefits derived from using these strategies [9]. It helps stimulate educational organizations improve the quality of their activity and it acts as a driving force for a national movement on quality improvement.

Another excellence model which can be used to compare and assess the activity of a university one belongs to, is the one managed by the European Foundation for Quality 
Management - EFQM; this also lies at the basis of the J.M. Juran Romanian Prize for Quality. The evaluation framework also includes 7 criteria, out of which the first 5 are considered enablers, while the others, results of the organization [10].

Their assessment takes place in different ways. Thus, the element taken into account when assessing enablers is the approach, which has to be well documented; its processes have to be well defined, in accordance with the requirements of the interested parties; it has to be implemented and carried out in a structured, well-planned and accurate manner. The effectiveness of the approach has to be proved by regular measurements, whose results have to be used in order to identify the best practices and enhancement opportunities etc.

The assessment of the results is carried out with a view to: the positive tendencies and the continuity, if it exists, in attaining performances; the targets have to be adequate, they have to be met, while the results have to be close to those of the leading organizations; the obtained results have to be an effect of the approach, they have to reflect relevant domains etc.

As can be seen, on the basis of these models, an educational organization is assessed much more rigorously, and the results of the assessments show indeed the tendency towards all the meanings of quality. We have to show that, when we speak about quality, we have to prove how we do it, how we know we are doing well and how we improve things.

At the end of the year 2008, after an internal benchmarking against the Romanian National Quality Award - Juran National Award criteria (containing the similar criteria with those of the European Quality Award-EQA: Leadership, Policy and strategy, People, Partnership and Resources, Processes, Customer Results, People Results, Society Results and Key Performance Results) the A.E.S. was externally evaluated and obtained two awards: Quality Award for Education and Excellence Award for Continuous Learning, Improving and Innovation.

\section{Conclusions:}

There is more and more talk about a quality culture. It presupposes the acquisition of a certain approach to quality, rather than of a system; it presupposes the focus should be on the student; the student has to be considered not a product or a client, but a partner.

Among other things, quality culture implies the periodic reassessment of the university's mission, values and vision, the personal example set by leaders, interaction with stakeholders, risk management, acknowledgement of the employees' efforts, taking the "best in class" as a role model, etc.

A strong quality culture no longer needs a quality assurance system; it relies on mutual trust among all partners in the educational act; it is no longer implemented; it is built step by step, action by action, until it becomes reality.

Taking into account the complexity of socio-economic life and the dynamic nature of quality (defined in the academic environment through its opposition to non-quality more than through its own description, reflecting various cultural, political, national, regional or global socio-economic outlooks), we believe that universities in Romania need to establish their own value system; also, their target should go beyond meeting certain imposed criteria; they ought to compare themselves with standards of excellence awards requirements.

Attaining excellence in the entire activity of a university is the only factor which can place it among the first, at an international level, implicitly leading to acknowledgement of the merits of both its professors and its students. 


\section{References}

1. Ekong D; Escotet M.A.; Karani A.; Cappon P.; Orozco Silva; Brun J. M. - Quality of Higher Education, Final Report, Comission II, 2003;

2. Pneumaticos T.- More quality to the quality policy of education, Bologna process, National Reports 2004 - 2005, Cyprus;

3. Sârbu R, Ilie A.G., Enache A.C., Dumitriu D. - The Quality of Educational Services in Higher Education - Assurance, Management or Excellence?, Amfiteatrul Economic, Volume XI (2009), issue 26 (June), Editura A.S.E.

4. X X X - Law no. 87/10.04.2006 for approving the Ordinance no 75/12 July 2005 referring to the assurance of quality of education;

5. X X X - European Association for Quality Assurance in Higher Education - Standards and Guidelines for Quality Assurance in the European Higher Education Area, Multiprint, Helsinki, Finland, 2005;

6. X X X - Developing an Internal Quality Culture in European Universities, Report on the Quality Culture Project, Round II, 2004, E.U.A., Rue d'Egmont 13 B-1000, Brussles Belgium;

7. X X X - IWA 2: 2007 - Quality Management systems - Guidelines for application of ISO 9001:2000 in education;

8. X X X - The Romanian Agency For Quality Assurance in Higher Education Methodology ;

9. Education Criteria for Performance Excellence, Baldrige National Quality Program;

10. http://www.fundatia-juran.ro/excelenta.php . 